\title{
Examining the Design of Microlearning for Korean Adult Learners
}

\author{
Hyo-Jeong So ${ }^{\mathrm{a}}$, Hyeran Lee ${ }^{\mathrm{a}}$ \& Seak-Zoon Roh ${ }^{\mathrm{b}}$ \\ ${ }^{a}$ Ewha Womans University, Korea, \\ ${ }^{\mathrm{b}}$ Sungshin Women's University, Korea
}

Corresponding author: hyojeongso@ewha.ac.kr

\begin{abstract}
Considering the increasing demand for microlearning in informal learning spaces, the main purpose of this research is to examine the design of microlearning perceived by adult learners and experts in Korea. The research questions include: (1) what modality and content length do adult learners perceive to be relevant for microlearning? (2) what content areas do adult learners perceive to be relevant for microlearning? and (3) what are the expected impacts and future directions of microlearning perceived by the experts? The participants include 11 e-learning experts and 326 adult learners working in the fields of science and technology. Data were collected from the learner survey, focus group interview, and expert survey. Overall, this study found that adult learners tend to have some conflicting opinions about the content areas perceived to be relevant for e-learning and microlearning. The design of content that takes the modality of video consumed within 3-5 minutes was considered to be the most relevant for microlearning. Experts perceived that microlearning is an efficient and effective direction for adult learners to enhance professional knowledge and to broaden informal learning opportunities. However, the experts were less positive about the potential of microlearning for increasing convergence research and learning transfer. There was a considerable gap between desirability and feasibility in the directions toward integrating microlearning with advanced technologies. Based on the key findings, we discuss some implications concerning the design of microlearning for adult learners' informal learning.
\end{abstract}

So, H-J., Lee, H., Roh, S-Z. (2020) Examining the Design of Microlearning for Korean Adult Learners. Computer-Based Learning in Context, 2(1), 40-53.

Keywords: microlearning, microlearning content, microlearning design, adult learners, informal learning

\section{Introduction}

Education is no longer locked in formal settings. While the existing education paradigm emphasizes the efficiency of knowledge delivery and transfer, education in the information age necessitates the fundamental change in how learners construct their own knowledge and develop core competencies as $21^{\text {st }}$ century learners (Collins \& Haverson, 2018). Subsequently, these changes in the educational paradigm require the design of learning environments that support adult learners' opportunities for lifelong learning (learning through own's lifespan) and lifewide learning (learning in many spaces) (Banks et al., 2007; Jackson, 2012). This means the growing criticality of 'informal learning' spaces where learning happens mostly in self-directed ways beyond the conventional structured learning methods. In such informal learning spaces, adult learners enter and participate in a learning environment voluntarily, mainly motivated by their interests and needs.

The proliferation of smart devices and the advancement of web environments have affected how people learn and interact. Brown and Adler (2008) argue that longtail learning emerges with almost unlimited choices of online learning content in the participatory web 2.0 environment. Another noteworthy trend in recent years is the rise of microlearning that delivers information in the form of short video clips (e.g., TED, Instructables), infographics, and card news. Tony Bingham at the 2017 ATD conference emphasized that microlearning is one of the most important global trends in human resource development (HRD). A research study with 596 talent development professionals found that $33 \%$ of them were already using microlearning in their companies and $41 \%$ had a plan to start microlearning soon (ATD research, 2017). For instance, IBM (2017) introduced the Your Learning platform with Watson technology that provides an intelligent personalized learning content based on the analytics of individual employees' learning needs. 
The growing demand for microlearning can be explained by two factors. The first factor is related to the social phenomenon from just-in-case learning to just-in-time learning since the kind and amount of knowledge that an individual has to acquire is rapidly increasing. From the learner's point of view, microlearning content accessible via computers and mobile devices is advantageous for the on-the-go consumption, minimizing temporal and spatial constraints. The second factor reflects the characteristics of so-called $21^{\text {st }}$ century workers or Generation $\mathrm{Z}$ workers. This new generation of workers is social and mobile. Microlearning is viewed as a way to bring their social and mobile behaviors into learning experiences.

Despite such growing interests and demands toward microlearning, there is little empirical research available about how to design microlearning relevant for adult learners. Our previous review of the existing literature on microlearning indicates that little academic research studies had been conducted in this area (So \& Lee, 2017). We conducted a systematic literature review on the topic of microlearning published in the years from 2003 to 2017 and identified 74 articles. Only 13 articles reported empirical findings, and the existing articles on microlearning were mostly about theoretical/conceptual discussions and technical development. Studies with empirical findings present data related to the effectiveness and benefits of microlearning (e.g., Hanshaw \& Hanson, 2018; Leach \& Hadi, 2017). Some information about the design of microlearning content and topic areas was available in these studies. Microlearning content types include various modalities such as video, audio, and visuals with concise information. Topic areas were also diverse, including economics, medical/health, language, and computer (refer to So \& Lee, 2017 for more details). On the whole, while some intervention-based studies exist, there is still a lack of research that can inform the design of microlearning, especially in the context of informal learning for adult learners.

With this backdrop, the main purpose of this research is to examine the perception of adult learners and experts toward the design of microlearning in order to draw design implications. This study was initiated with the assumption that microlearning is not simply truncated tiny information but is a stand-alone manageable content that carries meaningful information and knowledge on its own (Giurgiu, 2017; Hug, 2015). Another assumption behind this study is that not all types of knowledge may be relevant for microlearning, and certain types of knowledge can be better designed and delivered via microlearning (Enmerson \& Berg, 2018; Fox, 2016). To this end, we conducted a research study with e-learning experts and adult learners in the field of science and technology in Korea to examine the following research questions: (1) what modality and content length do adult learners perceive to be relevant for microlearning?; (2) what content areas do adult learners perceive to be relevant for microlearning?; and (3) what are the expected impacts and future directions of microlearning perceived by the experts? These are the questions that this study aimed to answer, ultimately drawing implications and insights for the design of microlearning.

\section{Theoretical Background}

2.1 What Microlearning Is. Initially, the term microlearning appears in the literature of e-learning, which generally refers to the delivery of learning, training or education programs by electronic means (Li et al., 2009). In e-learning, various information and communication technologies (ICTs) are used to mediate both synchronous and asynchronous teaching and learning activities (Sangrà et al., 2012). As shown in Table 1, there are numerous definitions of microlearning found in the existing literature. Generally, microlearning is the term that presents "an abbreviated manner of expression for all sorts of short-time learning activities with microcontent" (Hug, 2015, p.492). Hug (2005) also presents six dimensions of microlearning namely (1) time, (2) content, (3) curriculum, (4) process, (5) modality, and (6) learning type. Often, the term microlearning is interchangeably called bite-sized learning to emphasize the nature of small-sized content (Soh, 2017). There are more-technically oriented definitions of microlearning since microlearning can be offered across web 2.0 technologies as well as traditional learning management systems (Grevtseva et al., 2017). For instance, Sánchez-Alonso et al. (2006) defined microlearning as an independent unit connected to learning objects that are easy to reuse in various learning contexts. The common components of microlearning are characterized in terms of small and short digital content that can be consumed in 10 minutes (e.g., Shail, 2019; Torgerson \& Iannone, 2019). 
Table 1. Various definitions of microlearning.

\begin{tabular}{ll}
\hline Hug (2015) & $\begin{array}{l}\text { An abbreviated manner of expression for all sorts of short-time learning } \\
\text { activities with microcontent. }\end{array}$ \\
Jomah et. al (2016) & $\begin{array}{l}\text { All about getting your eLearning in small doses, as tiny bursts of training } \\
\text { material that you can comprehend in a short time. } \\
\text { What one has learned, in small, focused steps, (...) self-contained, with its } \\
\text { Khurgin (2015) }\end{array}$ \\
$\begin{array}{l}\text { own learning objective (...) as short as possible but as extensive as necessary. } \\
\text { Relatively small, focused learning units consisting of condensed learning } \\
\text { activities (usually one to } 10 \text { minutes), available on multiple devices. }\end{array}$ \\
Torgerson \& Iannone (2019) & Any learning content that can be consumed in 10 minutes. \\
\hline
\end{tabular}

Despite increasing interest in microlearning, a few studies empirically analyzed the effects of microlearning. Overall, empirical studies generally reported that microlearning had positive effects on learning. Leach and Hadi (2017) conducted a study where MOOCs were designed with a modular approach as microlearning. Since the intention of many MOOC learners is not on completing the entire course, Leach and Hadi challenged the assumption about the linear completion of the entire course as ideal participation in MOOCs. Instead, they adopted modular MOOCs where learners can choose any unit to start with and complete courses flexibly. As microlearning, each modular unit was designed to include own learning goals, activities, and assessment. Learners were awarded a badge for the completion of each unit. Hesse et al. (2019) investigated the effectiveness of microlearning on dairy workers. Participants were given three videos about tube feeding, bottle feeding, and colostrum quality for about 10 minutes with a quiz. In the study, 64 employees took the questionnaire after taking microlearning training and 50 (78\%) of them reported that their confidence in completing tasks increased after training. Fagerstrøm et al. (2017) examined the impact of microlearning developed as a mobile application with flip cards for training healthcare professionals in Norway. The study used a between-subjects design with a randomized selection that included two experimental groups and one control group. Two experimental groups used the mobile microlearning application whereas the control group was given traditional training with lectures and workshops. A pretest and posttest comparison were used to measure the knowledge gain concerning the use of coercion in working with mentally and socially handicapped people, which was the main content of the mobile application. The level of knowledge gains in the experimental groups was higher than that of the control group.

In the Korean context, Ju and Chung (2018) investigated the moderating effects of microlearning on the relationship between change readiness and willingness to change, and on the relationship between change competency and willingness to change among adult workers in the IT company. In this study, three different microlearning contents were provided to the participants, and the participation in microlearning was voluntary. They found that the participation rates in microlearning did not have a meaningful mediation effect. They speculated that the situation of the company at the time of the study might influence the participants and thus could affect the research result. Jung (2019) conducted a research study about developing microlearning contents and verifying its effectiveness through the usability evaluation. The usability indicators consisted of effectiveness, aesthetics, efficiency, ease of use, component display strategies, contents and structure, and degree of immersion. The usability score of all indicators in the microlearning content was higher than that of the general learning content.

2.2 Microlearning Design. Microlearning needs certain design considerations such as appropriate learning time, content type, and modality. Concerning the appropriate learning time, the ATD research (2017) found that learners tend to perceive segments lasting for two to five minutes the most effective for learning. Microlearning is designed as small chunks of learning content that learners can easily access in specific moments such as time breaks or on the move (Gabrielli et al., 2006). While typical lessons in e-learning consist of an opening, presentation, exercises, and closing, microlearning content may omit some elements to make small chunks of learning content (Jahnke et al., 2020). Microlearning content is also easily editable, applicable, and reusable in a form suitable for individual learner's needs (Polsani, 2003).

Concerning what to teach through microlearning, the existing literature indicates that microlearning is appropriate under certain learning conditions and activities. For instance, Fox (2016) contends that microlearning is inappropriate when students are learning something for the first time or complex knowledge and skills. Similarly, Jahnke et al. (2020) suggest that microlearning is appropriate when learning objectives focus on the level of "understanding" in the Bloom's taxonomy, and high-order thinking skills (e.g., deep analysis) is rather difficult to 
learn through microlearning. Microlearning is used to activate prior knowledge and to reinforce learning experiences (Hanshaw \& Hanson, 2018; Paul, 2016). Hence, microlearning is often designed as a follow-up or supplementary component of the large training program.

There are few established principles and guidelines available for the design of microlearning. We could locate only one research that specifically discussed the design of microlearning content for mobiles. Drawn from the analysis of the literature and interviews with industry professionals, Jahnke et al. (2020) propose eight design principles of mobile microlearning: (1) interactive microcontent for closing practical skill gaps (e.g., practical problems), (2) chunked courses, (3) instructional flow of activity-based model of instruction (e.g., sequencing, instant feedback), (4) system design (e.g., push notification, tracking), (5) supporting learner needs (e.g., the moment of need), (6) supporting social structures (e.g., connecting learners), (7) cost and affordable subscription model, and (8) curriculum that provides single lessons and may lead to certificates or degrees. While these are useful design guidelines, they were mainly drawn from the scholarly articles and expert opinions, and learners' perceptions about these design aspects were not reflected.

Thus far, a video has been the most common modality of delivering microlearning content. The design of microlearning, however, should go beyond small chunks of video clips and include strategies to engage learners in deeper learning processes (Major \& Calandrino, 2018). Jahnke et al. (2020) contend that the design of microlearning content for mobile platforms and devices is "shifting from a pure video watching approach to a more activity-based model of instruction in which the learner reads or watches something but then $\mathrm{s} / \mathrm{he}$ has to be active to apply the new knowledge" (p.28). Gamification has been used to make the design of microlearning content more interactive (Ahmad, 2018; Göschlberger \& Bruck, 2017). However, designing microlearning with the integration of advanced types of technologies such as augmented reality (AR), virtual reality (VR), and artificial intelligence (AI) has not been actively explored in the existing literature. Considering the demand for customizable content driven by the increasing amount of new information and knowledge that adult learners need to learn, the affordances of more interactive and intelligent technologies need to be explored in the design of microlearning.

\section{Method}

3.1 Research Context and Participants. For this study, the research team collaborated with the government-affiliated agency hat is the main provider of e-learning courses for enhancing the knowledge base and capacity of the science and technology workforce in Korea. At the time of the study, the agency was planning to develop a microlearning platform to extend its e-learning service and to meet the demands of adult learners' flexible learning opportunities. Further, the agency intended to establish a long-term plan toward providing courses about convergence research skills and the integration of advanced technologies into the design of microlearning. Thus, the research context provided a good opportunity to examine adult learners' perceptions of microlearning. Table 2 presents information about the participants and the data collection method for the respective research question.

Table 2. Research questions and data collection.

\begin{tabular}{|c|c|}
\hline Research Questions (RQs) & Data collection \& Participants \\
\hline $\begin{array}{l}\text { (1) What modality and content length do adult learners perceive to be } \\
\text { relevant for microlearning? }\end{array}$ & Learner survey $(N=326)$ \\
\hline $\begin{array}{l}\text { (2) What content areas do adult learners perceive to be relevant for } \\
\text { microlearning? }\end{array}$ & $\begin{array}{l}\text { Learner survey }(N=326) \\
\text { Focus group interview }(N=11)\end{array}$ \\
\hline $\begin{array}{l}\text { (3) What are the expected impacts and future directions of microlearning } \\
\text { perceived by the experts? }\end{array}$ & Expert survey $(N=13)$ \\
\hline
\end{tabular}

First, to investigate adult learners' perceptions about modality, content length, and content areas relevant to microlearning (RQs $1 \& 2$ ), participants in the study were recruited from adult learners who had taken at least one or more e-learning courses offered by the agency. Some courses (e.g., research ethics, lab safety) provided by this agency are mandatory for graduate-level students and Research \& Development (R\&D) professionals working in the fields of science and technology in the government-affiliated R\&D institutes in Korea. We gathered data through the learner survey and focus group interview. For the focus group interview, we selected 13 participants $(9$ males and 4 females) who completed two or more e-learning courses provided by the collaborating agency.

Second, we examined the experts' perceptions of the expected impact and future directions of microlearning through the survey (RQ3). Methods that involve experts (e.g., Delphi study, expert survey) are often used in the 
emerging field for generating diversified ideas, reaching a consensus on debatable issues, and making predictions on future trends (Sangrà et al., 2012). Since microlearning was a rather new field with uncertainly at the time of the study, we used the expert survey method to gather experts' opinions about the expected impact of microlearning and how future microlearning could be designed with the integration with new technologies. Examining experts' opinions was also helpful to set the desirable directions of the microlearning initiative for the agency that we worked with. We defined experts as people who had conducted and published academic research and/or those who had extensive practical experiences that could inform the design of microlearning. Since microlearning was discussed under the e-learning context at the time of the present study, we recruited experts who had been working mainly in the e-learning field. Due to the difficulty of locating relevant experts, we used a snowball sampling approach for the recruitment where we initially identified three experts with expertise in microlearning and then asked their recommendations for others eligible to participate in this study. Each participant received the information about the background, purpose, and method of the study through the telephone, e-mail, or in-person communication before agreeing to participate in the survey. The expert group included five experts who were university faculty members with extensive research experiences in e-learning, three from the government agencies that offer e-learning courses, and three from the industry sectors who were in charge of their organization's e-learning content development, including microlearning.

3.2 Data Collection and Analysis. Methodologically, we used the mixed method approach (Cresswell, 2003) to collect both quantitative and qualitative data from adult learners and experts. We chose the mixed method approach to hear the voice of our participants through the focus group interview (FGI) and open-ended responses as well as to identify overall trends from a large number of participants through a survey. Generally, FGI is used as a research tool that explores new perspectives on key issues (Vaughn et al., 1996). Since the topic of this research, microlearning, was relatively new at the time of the study, we selected FGI as a relevant method to hear learners' perspectives about the topic.

3.2.1 Learner Survey. The survey was conducted with a focus on deriving the design of microlearning from the learner's point of view. We designed the online survey that included questions about (a) the modality and content length of microlearning content (e.g., What is the most ideal media type of microlearning content?); and (b) the content areas perceived relevant to learn through microlearning (e.g., Which of the following R\&D topics do you think is relevant for microlearning?). A convenience sampling method was used to recruit participants for the survey. Through an exhaustive mailing list provided by the agency, an invitation to participate in the survey was sent out to the learners who had taken at least one or more online course(s) from the e-learning platform provided by the agency. In the online survey, the participants read the statement about the purpose of the study, and those who agreed with the statement moved to the next page to begin the survey. A total of 326 participants completed the online survey with valid responses. Descriptive statistics were used to analyze the mean and standard deviations (SD) of responses and rank orders.

3.2.2 Focus Group Interview. The purpose of a focus group interview (FGI) was to further examine what and how adult learners perceive the design of microlearning, mainly from the content consumer's perspectives. The FGI was conducted in two separate sessions at a meeting room, facilitated by the research team. The FGI was conducted for two hours with semi-structured questions that focused on the relevant topics for microlearning such as exploring potential topics, content properties, and content development. While various issues were discussed during the FGI, the present study focuses on the findings related to the content areas relevant to microlearning. The conversation during the FGI was audio-recorded and transcribed for the content analysis. The transcripts were analyzed to find common themes in the interview conversations through the constant comparison method (Corbin \& Strauss, 2015). Similar responses were grouped under conceptual headings to form categories and then core categories were identified as a major theme.

3.2.3 Expert Survey. The main purpose of the expert survey was to gather experts' perceptions of the expected impact of microlearning and the future directions of microlearning. The survey items were co-constructed with the e-learning personnel of the agency since the findings needed to inform the agency's future planning of the microlearning initiative such as the plan to provide courses about convergence research skills and the integration of advanced technologies into the design of microlearning. In the survey, we made it clear that adult learners in the statements refer to the R\&D professionals in science and technology with some information (e.g., types of learners, learning methods, range of courses offered, etc.) to help the experts to better understand the contextual factors. 
The first section of the study included the following five questions on a 5-point Likert scale $(1=$ Strongly disagree, $5=$ Strongly agree) concerning the expected impact of microlearning. Open-ended areas were provided in each question for the experts to provide elaborations for their response.

Q1: Microlearning will be effective in enhancing adult learners' professional knowledge.

Q2: Microlearning will be efficient in enhancing adult learners' professional knowledge.

Q3: Microlearning will enhance convergence research among adult learners.

Q4: Microlearning will improve adult learners' on-site application of learning (learning transfer).

Q5: Microlearning will increase adult learners' opportunities for informal learning.

The second section of the study focused on the future directions of microlearning that will be provided to science and technology R\&D professionals within the next five years. We provided the following five directions and asked the experts to indicate the desirability and feasibility of each direction on a 5-point Likert scale $(1=$ Strongly disagree, $5=$ Strongly agree). In the decision-making theory, desirability refers to the value of the certain activity's end-state (e.g., this activity is valuable) whereas feasibility refers to the means of achieving the activity's end-state (e.g., this activity is easy to implement) (Liberman \& Trope, 1998). The interaction between desirability and feasibility leads to conflicting choices, particularly when a certain activity is perceived to be high desirability but low feasibility (HD-LF) or low desirability but high feasibility (LD-HF) (Lu et al., 2013). By measuring both desirability and feasibility for the statements, we attempted to help the agency make a balanced choice for the future planning of the microlearning initiative.

Q1: The existing competency-oriented e-learning will be replaced by microlearning.

Q2: Microlearning content produced and shared by learners will be pervasive.

Q3: The provision of intelligent microlearning content, which analyzes the interests and needs of learners, will become more common.

Q4: The form of microlearning content will be combined with new technologies such as virtual reality, augmented reality, and the Internet of Things (IoT).

Q5: The use of microlearning content will become common in both formal and informal learning spaces.

The expert survey was distributed via email after the experts agreed on the research participation. Collected data were analyzed for descriptive statistics, and responses to open-ended questions were content analyzed to identify overall patterns and common themes across the experts' responses.

\section{Results}

4.1 Demographic Data. Table 3 shows the demographic data for the participants of this study. The participants included more male learners $(N=206,63.2 \%)$ than female learners $(N=120,36.8 \%)$. About $67 \%$ of the participants were in their $30 \mathrm{~s}(N=104,31.9 \%)$ and $40 \mathrm{~s}(N=115,35.3 \%)$. About half of the participants $(N=156,47.9 \%)$ indicated that they work in the research sector. Concerning the job type and position, there were more researchers $(N=215$, $66.0 \%)$ than administrative officers $(N=111,34.0 \%)$, and job positions were almost even across the entry, junior and senior levels. About $68 \%$ indicated that they hold a master's or doctorate degree, implying that the participants are highly educated learners. Concerning their academic major, the largest number of participants were from the natural science and engineering areas $(N=191,58.6 \%)$, followed by humanities and social science $(N=103,31.6 \%)$. In summary, the participants of this study were mostly researchers in their $30 \mathrm{~s}$ and $40 \mathrm{~s}$ with a master's or doctorate degree from the natural science and engineering fields who were engaged in research-related jobs. 
Table 3. Demographic data.

\begin{tabular}{|c|c|c|c|c|c|c|c|}
\hline Variable & Category & $N$ & $\%$ & Variable & Category & $N$ & $\%$ \\
\hline \multirow[t]{2}{*}{ Gender } & Male & 206 & 63.2 & \multirow[t]{2}{*}{ Job Position } & Entry-level & 111 & 34.0 \\
\hline & Female & 120 & 36.8 & & Junior-level & 122 & 37.4 \\
\hline \multirow[t]{4}{*}{ Age } & The 20s & 58 & 17.8 & & Senior-level & 93 & 28.5 \\
\hline & The 30s & 104 & 31.9 & \multirow[t]{3}{*}{ Final degree } & Bachelor & 103 & 31.6 \\
\hline & The 40s & 115 & 35.3 & & Master's & 91 & 27.9 \\
\hline & over $50 \mathrm{~s}$ & 49 & 15.0 & & Doctorate & 132 & 40.5 \\
\hline \multirow{4}{*}{ Organization } & Industry sector & 59 & 18.1 & \multirow[t]{4}{*}{ Major } & Natural science \& & 191 & 58.6 \\
\hline & Academic sector & 111 & 34.0 & & Engineering & & \\
\hline & Research sector & 156 & 47.9 & & Medical fields & 21 & 6.4 \\
\hline & & & & & $\begin{array}{l}\text { Humanities \& social } \\
\text { Science }\end{array}$ & 103 & 31.6 \\
\hline \multirow[t]{2}{*}{ Job type } & Researcher & 215 & 66.0 & & Other fields & 11 & 3.4 \\
\hline & Administrative officer & 111 & 34.0 & & Total & 326 & 100.0 \\
\hline
\end{tabular}

4.2 Modality of Microlearning. First, we asked the question about the modality of microlearning content, both media type and ideal length. As presented in Table 4, video (64.4\%) was perceived to be the most relevant modality for microlearning, followed by $21.5 \%$ in visual images (e.g., cartoons, infographics), and $13.5 \%$ in the text (e.g., reports, news articles). Concerning the ideal length of microlearning content, as shown in Figure 1, the participants felt that the content length between 3-5 minutes is the most ideal for microlearning, followed by 7-10 minutes $(28.2 \%)$ and 5-7 minutes $(16.6 \%)$.

Table 4. Media type of microlearning content $(N=326)$.

\begin{tabular}{llr}
\hline Rank & Media type & $\boldsymbol{N ( \% )}$ \\
\hline 1 & Video & $210(64.4)$ \\
2 & Visual images & $70(21.5)$ \\
3 & Text & $44(13.5)$ \\
4 & Others & $2(0.6)$ \\
\hline
\end{tabular}

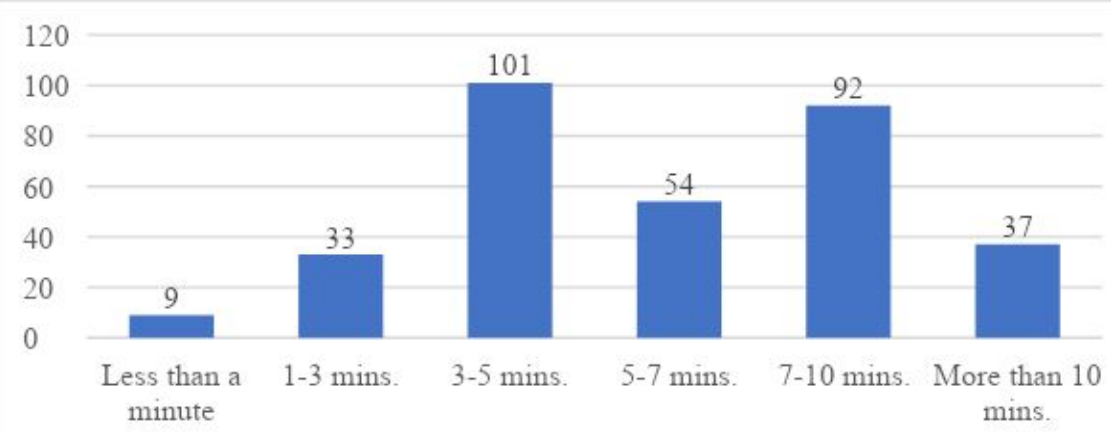

Frequency

Figure 1. Ideal length of microlearning content $(N=326)$.

4.3 Content Areas Relevant for Microlearning. In the learner survey, we examined the types of R\&D topics the adult learners perceived the most relevant for microlearning. In this question, multiple responses were allowed. Table 5 summarizes the top five-ranked topics. Overall, the data indicate that the participants perceived the needs of microlearning in the topic areas that deal with the latest issues and are beneficial for their creative ideas. The needs 
of domain-specific topics that deal with deeper knowledge levels were perceived to be less relevant for microlearning.

Table 5. Rank-order of microlearning content areas.

\begin{tabular}{llr}
\hline Rank & Content area & $\boldsymbol{N ( \% )}$ \\
\hline 1 & Latest issues in science and technology & $144(44.2)$ \\
2 & Cases of creative development & $129(39.6)$ \\
3 & Practical interpretation skill & $80(24.5)$ \\
4 & R\&D planning & $79(24.2)$ \\
5 & Creating ideas & $78(23.9)$ \\
\hline
\end{tabular}

Relevant content areas for microlearning were further examined in the FGI. The analysis of the FGI data revealed two major themes about content areas perceived by the participants as relevant for microlearning: demand for the current topics and coupling of microlearning and e-learning content. First, throughout the FGI session, it became clear that the demand for microlearning that deals with the latest issues and current trends in the R\&D fields was high. Examples of sub-topics mentioned by the participants include big data, artificial intelligence, new policies in other countries, and trends of emerging technologies and start-up companies. The participants indicated the need for the hub where they could easily access the latest articles, research issues, and trends in the science and technology field. Another highly-demanded area was more information- or idea-oriented such as the question $\&$ answer section to share cross-field ideas and statistical data. It was worthy to note that the participants equally pointed out the dilemma that may arise with the currentness of microlearning content. They raised questions about the efficiency of developing microlearning content that needs frequent content updating, which would increase the content production cost.

Second, the participants perceived that microlearning is better suited to deliver key concepts and knowledge of science and technology R\&D fields, whereas e-learning is more effective to deliver advanced deeper levels of knowledge. Certain topics like research ethics and laboratory safety are essential for most professionals working in the science and technology R\&D field. The participants indicated that such common topics require an acceptable level of knowledge mastery, which can be better learned in lecture formats via e-learning. As shown in a T-shaped structure in Figure 2, they also suggested that domain-specific information (e.g., regulations and laws) can be learned by e-learning, coupled with the provision of microlearning content in domain-neutral areas such as communication, leadership and humanity topics.

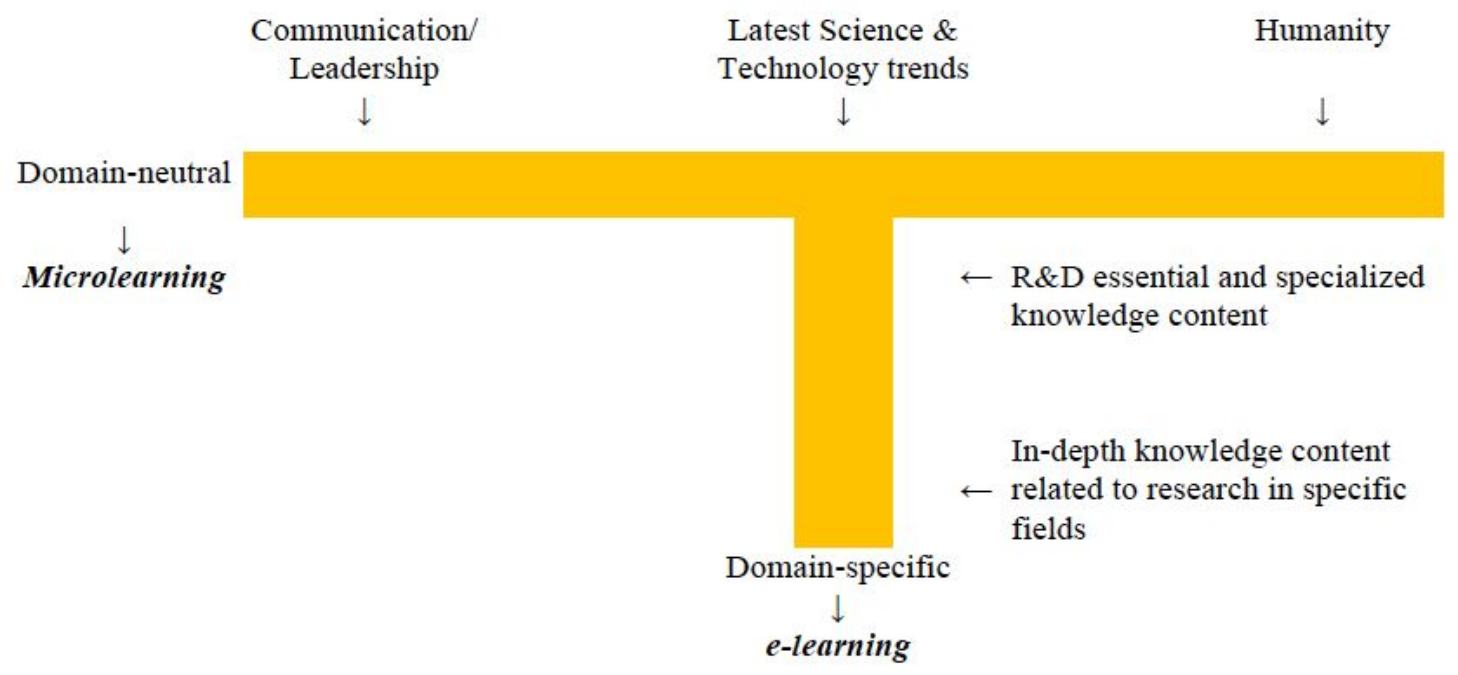

Figure 2. Microlearning for domain-neutral and e-learning for domain-specific topics. 
4.4 Expected Impact and Future Directions of Microlearning. Concerning the expected impact (see Figure 3), the experts anticipated that microlearning would greatly increase informal learning experiences of the targeted adult learners (mean $=4.36, S D=.67$ ). Further, they expected that microlearning would be effective (mean=4.18, $S D=.60$ ) and efficient (mean=4.18, $S D=.75$ ) in promoting their professional knowledge. They were less positive about the statements that microlearning would promote convergence research skills (mean=3.82, $S D=.98$ ) and improve the on-site application (learning transfer) (mean $=3.73, S D=.64$ ). Some of the open-ended responses provided by the experts are:

- Since microlearning deals with practical knowledge and conceptual units, it is easy to find and refer to them when searching for unit knowledge in the workplace. Therefore, although microlearning may not strengthen work expertise fully, I think it will help efficient and effective learning compared to the formal learning format.

- I am skeptical that microlearning will increase convergence research. Voluntary participation among researchers may be a difficult area to predict with the use of microlearning content because convergence research is a social problem between people, even if the core research results are made and distributed as a content.

- It is expected that microlearning can play a role in getting new creative ideas. However, applying knowledge to the workplace of learners is influenced by other factors, and an appropriate learner support system must be provided to increase the success rate of learning transfer.

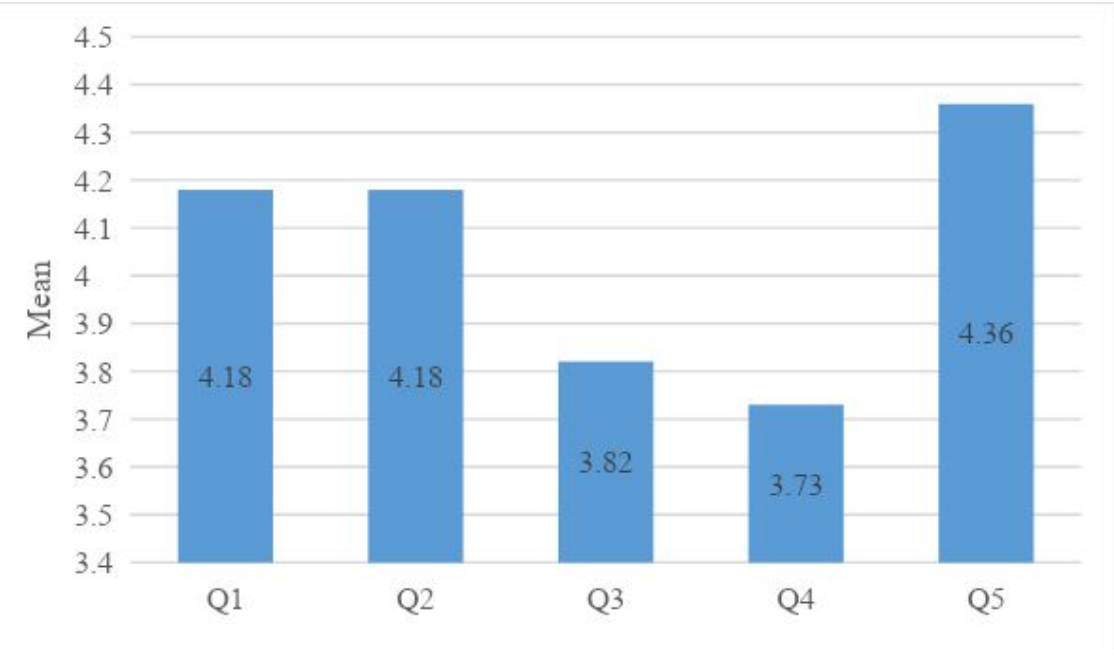

Q1: Microlearning will be effective in enhancing adult learners' professional knowledge.

Q2: Microlearning will be efficient in enhancing adult learners' professional knowledge.

Q3: Microlearning will enhance convergence research among adult learners.

Q4: Microlearning will improve learners' on-site application of adult learning (learning transfer).

Q5: Microlearning will increase adult learners' opportunities for informal learning.

Figure 3. Expected impact of microlearning.

Next, about the future directions of microlearning within the next five years (see Table 6), the experts viewed the provision of intelligent microlearning content (mean $=4.50, S D=.52$ ) as being the most desirable direction, followed by incorporating new technologies such as VR, AR and IoT (mean=4.27, $S D=.64$ ), and using microlearning content commonly in both formal and informal learning spaces (mean=4.27, $S D=.90$ ). On the other hand, the desirability levels of replacing e-learning by microlearning (mean $=3.18, S D=1.40$ ) and the pervasiveness of microlearning content produced by learners (mean $=3.82, S D=.87$ ) were relatively lower. As visualized in Figure 4, the experts held differing perceptions regarding the feasibility for each direction. The highest feasibility was the direction that "Q5: The use of microlearning content will become common in both formal and informal learning spaces" (mean $=3.64$, $S D=1.02$ ). The pattern of high desirability but low feasibility (HD-LF) was observed in the direction "Q4: The form of microlearning will be combined with new technologies such as virtual reality, augmented reality, and IoT". "Q1: The existing competency-oriented e-learning will be replaced by microlearning" was perceived to be low levels of 
desirability and feasibility (LD-LF). Overall, the experts predicted that certain directions have a considerable gap between what is desirable and what can be realized in practices within the next five years. Some of the open-ended responses provided by the experts are:

- The purposes of e-learning and microlearning are different, so the degree of desirability is low. But considering the changing preference of learners, the degree of realization is judged to be higher.

- The learning value of self-produced and shared microlearning content is great. But considering the characteristics of Korean learners, it will not be easy to implement.

- Applying the content recommendation algorithm by analyzing the learner's learning pattern will gradually become more sophisticated and universal.

- Integrating with new technology is the direction in which the learning content as a whole will evolve. But I think the degree of feasibility within 5 years is low. There is a higher possibility in K-12 education than the adult education market.

- The use of microlearning is more suitable for informal learning.

Table 6. Mean and rank-order of future directions.

\begin{tabular}{|c|c|c|c|c|c|}
\hline \multirow[t]{2}{*}{ Direction } & \multicolumn{3}{|l|}{ Mean $(S D)$} & \multicolumn{2}{|l|}{ Rank-order } \\
\hline & Desirability & Feasibility & Difference & Desirability & Feasibility \\
\hline $\begin{array}{l}\text { Q1: The existing competency-oriented } \\
\text { e-learning will be replaced by } \\
\text { microlearning. }\end{array}$ & $\begin{array}{l}3.18 \\
(1.40)\end{array}$ & $\begin{array}{l}3.27 \\
(1.19)\end{array}$ & -0.09 & 5 & 4 \\
\hline $\begin{array}{l}\text { Q2: Microlearning content produced } \\
\text { and shared by learners will be } \\
\text { pervasive. }\end{array}$ & $\begin{array}{l}3.82 \\
(.87)\end{array}$ & $\begin{array}{l}3.36 \\
(.80)\end{array}$ & 0.45 & 4 & 3 \\
\hline $\begin{array}{l}\text { Q3: The provision of intelligent } \\
\text { microlearning content, which analyzes } \\
\text { the interests and needs of learners, will } \\
\text { become more common. }\end{array}$ & $\begin{array}{l}4.50 \\
(.52)\end{array}$ & $\begin{array}{l}3.50 \\
(.97)\end{array}$ & 1.00 & 1 & 2 \\
\hline $\begin{array}{l}\text { Q4: The form of microlearning content } \\
\text { will be combined with new } \\
\text { technologies such as virtual reality, } \\
\text { augmented reality, and the Internet of } \\
\text { Things (IoT). }\end{array}$ & $\begin{array}{l}4.27 \\
(.64)\end{array}$ & $\begin{array}{l}3.27 \\
(1.00)\end{array}$ & 1.00 & 2 & 4 \\
\hline $\begin{array}{l}\text { Q5: The use of microlearning content } \\
\text { will become common in both formal } \\
\text { and informal learning spaces. }\end{array}$ & $\begin{array}{l}4.27 \\
(.90)\end{array}$ & $\begin{array}{l}3.64 \\
(1.02)\end{array}$ & 0.64 & 2 & 1 \\
\hline
\end{tabular}




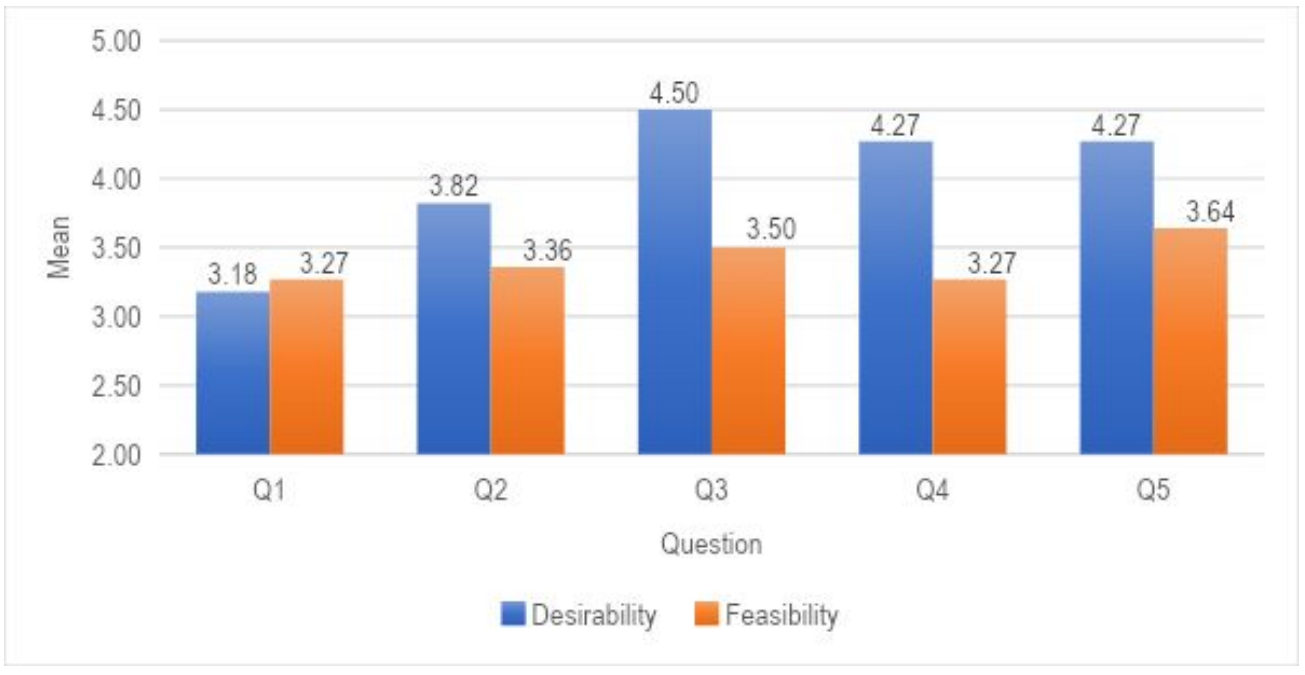

Figure 4. The gap between the desirability and feasibility of each direction.

\section{Discussion and Conclusion}

In this study, we examined what Korean adult learners in the science and technology R\&D fields perceive the design of microlearning together with the expert opinions on the impact and future directions of developing microlearning. In this section, we revisit each research question and discuss some implications of the key findings.

Regarding the first research question on the modality and content length perceived relevant for microlearning, the most favorable modality was the video content that can be consumed within 3-5 minutes. The participants were less favorable about the content being extremely short (less than 3 mins) or more than 10 minutes. This finding is consistent with the ATD research (2017) that found segments within 2-5 minutes most effective for microlearning. Video (64\%) was perceived to be the most useful modality for microlearning. Text content (e.g., report) was less preferred than video and images, which may imply the learners' preference toward the more visual modality.

The second research question examined the content areas that our target learners perceived to be relevant for microlearning, given the existing literature (e.g., Enmerson \& Berg, 2018; Fox, 2016) suggesting that certain types of knowledge can be better designed and delivered via microlearning. For our target learners, highly demanded content areas for microlearning were the latest issues in the science and technology field, practical skills, and creative ideas. Overall, both the survey and FGI findings consistently indicate that the 'currentness' of information and knowledge characterizes the highly demanded content area for microlearning. Such demands may indicate that these adult learners were in the $\mathrm{R} \& \mathrm{D}$ situation that they had to constantly acquire and digest the current information to follow the fast changes happening in their research field.

From the key findings of the research questions 1 and 2, we found that e-learning was perceived to be relevant for acquiring deeper knowledge whereas microlearning is effective for obtaining topical issues and current information. Behind this idea were the separation of content areas relevant for microlearning (e.g., 3-5 mins video clip) and e-learning (e.g., longer timeframe, a series of modularized content). That is, content modality and topic areas appear to interact to influence the participants' perception concerning what is relevant for microlearning and e-learning. In addition, the adult learners perceived that domain-specific information that requires certain levels of knowledge mastery can be delivered via e-learning while microlearning can be more relevant for domain-neural areas (e.g., communication and leadership skills). Based on these findings on modality and content areas, we suggest that organizations that intend to develop microlearning can consider the dual structure of the content delivery mode as shown in Table 7. In this mode, relatively stabilized content is delivered via the e-learning mode with a longer learning time whereas topical and dynamic content is designed as microlearning to support the on-demand and on-the-go consumption easily accessible by mobile devices. By doing so, learners who want to broaden their knowledge on topical and dynamic content can take microlearning courses while those who want to deepen their knowledge on more stabilized areas can take e-learning courses. 
Table 7. Dual structure for the content delivery mode.

\begin{tabular}{lll}
\hline Nature of topics & Content delivery mode \\
\hline - & Topical issues & Microlearning (less than 5 minutes) \\
- $\quad$ Current information & \\
\hline - & Stabilized topics & \\
- & $\begin{array}{l}\text { Domain-specific topics requiring } \\
\text { deeper understanding and certain levels } \\
\text { of knowledge mastery }\end{array}$ & \\
\hline
\end{tabular}

Regarding the third research question about the expected impact and future directions of microlearning, the expert perceived that microlearning is an efficient and effective direction to support our target learners' professional knowledge and to broaden informal learning opportunities. The experts, however, were less positive about the potential of microlearning for increasing convergence research and learning transfer, indicating that realizing such impacts require additional support beyond the delivery of necessary content. Regarding the future directions of microlearning, we found that considerable gaps exist between desirability and feasibility in the directions about integrating microlearning with advanced technologies such as AI, VR, AR, and IoT. While more advanced services for microlearning such as IBM Your Learning has been developed, intelligent content with analytics functions has not been pervasively used in the field.

The decision-making theory suggests that areas with high desirability but low feasibility (HD-LF) lead to conflicting situations (Lu et al., 2013). Organizations that plan for a direction to design microlearning with more interactive and intelligent functions beyond static video clips are likely to face the trade-off between desirability and feasibility. Establishing a clear vision for microlearning within near and long-term planning will be a necessary step for any organization that intends to adopt microlearning at a larger scale. Further, to identify the degree of feasibility, we suggest that it is essential for organizations to evaluate their own capacity for designing, developing, and managing microlearning. In general, the approaches of developing individual microlearning content can be divided into three types: (a) in-house development where planning, development, and operation of microlearning content is carried out within the institution providing training courses, (b) outsourcing production where microlearning content is developed by external specialist or companies, and (c) consortium model where multiple agencies collaborate on the planning, development, and operation of microlearning content. Given that many organizations do not have an in-house development team or have limited staff for the in-house development, a consortium model where multiple agencies collaborate in the development and dissemination of microlearning content can be a feasible way that can quickly generate relevant content while saving production cost.

The current study also carries an important implication for the changing paradigm of content design and development. With the rise of microlearning, learners do not have to learn in a linear way. As the nature of content delivered via microlearning tends to be dynamic, topical, and interest-driven, the structure for developing content needs to be congruent with this trend. That is, it is essential to develop a mechanism for rapidly generating and disseminating microlearning content. Hence, the current divide between content consumers and content providers may not be a viable model. A new convergent model where the content consumer also generates and disseminates microlearning content may be a more sustainable model for microlearning, as already witnessed in the rise of user-generated video content.

This study focused on the design of microlearning for Korean adult learners in the fields of science and technology. Understanding the interplay of cultural and contextual factors is essential in the design of culturally-responsible computer-based learning environments (Baker et al., 2019). As the socio-cultural factor of the present study, it is important to note that the Korean government has been promoting several initiatives toward building the creative economy with the workforce with convergence research skills. Under this policy movement, the R\&D professionals, like those who were the target participants of this study, have been facing the demand from their organizations to constantly update their knowledge and skills. While microlearning was proposed as a potential approach to meet such demands for Korean adult workers' informal learning, this study suggests that not all content areas are appropriate for microlearning, as presented in Table 7. To better meet the needs of individual adult learners, there should be more efforts to understand the possibility to provide customizable and adaptive learning content.

Understanding the unique characteristics of adult learners and the culture of their organizations is also an important area to design meaningful microlearning content. The existing literature suggests that adult learners tend 
to be autonomous, self-directed, and goal-oriented (Cercone, 2008). The design of microlearning can leverage these characteristics of adult learners to meet their learning needs coming from both external (e.g., demand from the organization) and internal aspects (e.g., curiosity, joy of learning new knowledge and skills). Since the present study focused on the adult learners' perceptions about the form and content of microlearning, we could not gain deep insights about such contextual and individual factors that are likely to affect adult learners' motivation to take microlearning courses. Definitely, these are the promising areas that future research can examine for deeper understandings of the cultural and contextual factors that Korean adult learners are situated in.

From this study, we found that there is a lack of consensus on what constitutes microlearning, indicating the semantic and epistemological differences and the need for redefining microlearning from the content consumers' perspectives. Whether microlearning content delivers merely information rather than knowledge is a debatable issue. Consequently, how to help learners transcend from the information consumption stage to the knowledge building stage is an important area for future research.

Some limitations of the current study should be noted. First, since this study focused on adult learners who tend to be highly educated and are working in the professional fields in Korea, the findings may not be generalizable to other groups of adult learners with different backgrounds. Second, since the participation in the learner survey was voluntary, the findings do not represent the opinion of all adult learners who took courses from the agency This limits the generalizability of the findings. Third, our findings are mainly descriptive and did not include inferential analyses. We suggest that future research can examine adult learners' needs about microlearning in terms of their demographic characteristics. In addition, future research can include in-depth investigations such as technology platforms, curriculum, assessment, learning goals, and activities to better understand adult learners' needs about microlearning.

Despite these limitations, we believe that this study provides important implications for the design of microlearning and the directions for future research and development. Considering the high demand and adoption of microlearning modalities by adult learners, we suggest the need for more empirical research on microlearning.

\section{Acknowledgments}

This research was supported by the Korea Institute of Human Resources Development in Science \& Technology (KIRD). This paper is an extended version of the paper presented at the 2018 International Conference on Computers in Education (ICCE), Manila. We would like to thank all the participants who helped this research project. 


\section{References}

ATD research (2017). Microlearning: Delivering bite-sized knowledge. Retrieved on September 10, 2019 from https://www.td.org/research-reports/microlearning-delivering-bite-sized-knowledge

Baker, R. S., Ogan, A. E., Madaio, M., \& Walker, E. (2019). Culture in computer-based learning systems: challenges and opportunities. Computer-Based Learning in Context, 1(1), 1-13.

Banks, J. A., Au, K. H., Ball, A. F., Bell, P., Gordon, E. W., Gutiérrez, K. D., Heath, S. B., Lee, C. D., Lee, Y., Mahiri, J., Suad Nasir, N., Valdés, G., Zhou, M. (2007). Learning in and out of school in diverse environments: Lifelong, lifewide, lifedeep. Seattle, WA: The LIFE Center (The Learning in Informal and Formal Environments Centre) \& Center for Multicultural Education, University of Washington.

Bingham, T. (2017). ATD 2017 opening presentation. Retrieved on September 10, 2019 from https://www.worldhrdcongress.com/HRD/images/hrd/atd/2017/Tony\%20Bingham\%20Presentation_ATD\% 202017.pdf

Brown, J., \& Adler, R. P. (2008). Open education, the long tail, and learning 2.0. Educause Review, 43(1), 16-20.

Cercone, K. (2008). Characteristics of adult learners with implications for online learning design. AACE Journal, 16(2), 137-159.

Collins, A., \& Halverson, R. (2018). Rethinking education in the age of technology: The digital revolution and schooling in America. New York, NY: Teachers College Press.

Corbin, J., \& Strauss, A. (2015). Basics of qualitative research: techniques and procedures for developing grounded theory (4th ed.). Los Angeles, CA: Sage.

Creswell, J. W. (2003). Research design: Qualitative, quantitative, and mixed methods approaches (2nd ed.). Thousand Oaks, CA: Sage.

Emerson, L. C., \& Berge, Z. L. (2018). Microlearning: Knowledge management applications and competency-based training in the workplace. Knowledge Management \& E-Learning, 10(2), 125-132.

Fagerstrøm, A., Gulliksen, M., \& Grønli, T. M. (2017, March). Microlearning in Educating Healthcare Professionals. In The 2017 International Conference on Advanced Technologies Enhancing Education (ICAT2E 2017). Atlantis Press.

Fox, A. (2016). Microlearning for effective performance management. TD Magazine, 70(4), 116-117.

Gabrielli, S., Kimani, S., \& Catarci, T. (2006). The design of microlearning experiences: A research agenda. In T. Hug, M. Lindner, \& P. A. Bruck, (Eds.). Microlearning: Emerging concepts, practices and technologies after e-Learning. Proceedings of Microlearning Conference 2005: Learning \& Working in New Media (pp. 45-53). Innsbruck, Austria: Innsbruck University Press.

Giurgiu, L. (2017). Microlearning an evolving elearning trend. Scientific Bulletin, 22(1), 18-23.

Göschlberger, B., \& Bruck, P. A. (2017). Gamification in mobile and workplace integrated microlearning. In iiWAS'17: The 19th international conference on information integration and web-based applications \& services, December 4-6, 2017, Salzburg, Austria.

Grevtseva, Y., Willems, J., \& Adachi, C. (2017). Social media as a tool for microlearning in the context of higher education. Proceedings of European Conference on Social Media (pp. 131-139). Academic Conferences and Publishing International.

Hanshaw, G. O., \& Hanson, J. (2018). A mixed methods study of leaders' perceptions of microlearning for professional development on the job. International Journal of Learning and Development. 8(3), 1-21. http://www.macrothink.org/journal/index.php/ijld/article/view/13198

Hesse, A., Ospina, P., Wieland, M., Yepes, F. L., Nguyen, B., \& Heuwieser, W. (2019). Microlearning courses are effective at increasing the feelings of confidence and accuracy in the work of dairy personnel. Journal of Dairy Science, 102(10), 9505-9511.

Hug, T. (2005). Microlearning: A new pedagogical challenge. In T. Hug, M. Lindner, \& P. A. Bruck (Eds.). Microlearning: Emerging concepts, practices and technologies after e-learning (pp. 7-12). Innsbruck, Austria: Innsbruck University Press.

Hug, T. (2015). Microlearning and mobile learning. In Yan, Z. (Ed.), Encyclopedia of mobile phone behavior (pp. 490-505). Hershey, PA: IGI Global.

IBM (2017). IBM's Your Learning and Watson - Together a game changer in learning. https://www.ibm.com/downloads/cas/G8DVQ9MB

Jackson, N. J. (2012). Lifewide learning: History of an idea. In N. Jackson, \& G. B. Cooper (Eds.), The lifewide learning, education \& personal development ebook (Chapter A1, 1-30). http://www.lifewideebook.co.uk/.

Jahnke, I., Lee, Y. M., Pham, M., He, H., \& Austin, L. (2020). Unpacking the inherent design principles of mobile microlearning. Technology, Knowledge and Learning, 25(3), 585-619. 
Jomah, O., Masoud, A. K., Kishore, X. P., \& Aurelia, S. (2016). Microlearning: A modernized education system. BRAIN. Broad Research in Artificial Intelligence and Neuroscience, 7(1), 103-110.

Jung, H. (2019). Design and implementation of micro-learning for corporate education. Journal of Digital Contents Society, 20(9), 1771-1780.

Ju, Y. \& Chung, J. (2018). A study on the relationship between change readiness, change competency, and willingness to change of middle management in the corporate education with microlearning. Journal of Corporate Education and Talent Research, 20(3), 103-132.

Khurgin, A. (2015). Will the real microlearning please stand up. https:/www.td.org/insights/will-the-real-microlearning-please-stand-up

Krueger, R. A., \& Casey, M. A (2015). Focus groups: A practical guide for applied research. Thousand Oaks, CA: Sage Publications.

Leach, M., \& Hadi, S. M. (2017). Supporting, categorising and visualising diverse learner behaviour on MOOCs with modular design and micro-learning. Journal of Computing in Higher Education, 29(1), 147-159.

Li, F. W., Lau, R. W., \& Dharmendran, P. (2009). A three-tier profiling framework for adaptive e-learning. Proceedings of the 8th International Conference on Advances in Web-based Learning, Aachen.

Liberman, N., \& Trope, Y. (1998). The role of feasibility and desirability considerations in near and distant future decisions: A test of temporal construal theory. Journal of Personality and Social Psychology, 75(1), 5.

Lu, J., Xie, X., \& Xu, J. (2013). Desirability or feasibility: Self-other decision-making differences. Personality and Social Psychology Bulletin, 39(2), 144-155.

Paul, A. M. (2016). How to make microlearning matter. HR Magazine. https:/www.shrm.org/hr-today/news/hr-magazine/0516/Pages/0516-microlearning.aspx

Polsani, P. R. (2003). Use and abuse of reusable learning objects. Journal of Digital Information, 3(4). https://journals.tdl.org/jodi/index.php/jodi/article/view/89/88

Sánchez-Alonso, S., Sicilia, M. A., García-Barriocanal, E., \& Armas, T. (2006). From microcontents to micro-learning objects-which semantics are required? (semantics for microlearning). In T. Hug (Ed.). Micromedia \& e-learning 2.0: Gaining the big picture. Proceedings of Microlearning Conference 2006 (pp. 295-303). Innsbruck, Austria: Innsbruck University Press.

Sangrà, A., Vlachopoulos, D., \& Cabrera, N. (2012). Building an inclusive definition of e-learning: An approach to the conceptual framework. The International Review of Research in Open and Distributed Learning, 13(2), 145-159.

So, H. J. \& Lee, H. (2017). Analysis and implications of the research trend on microlearning. Korea Science \& Art Forum, 30, 189-201.

Soh, Y. (2017). Bite-sized learning vs. microlearning: Are they one and the same? https:/elearningindustry.com/bite-sized-learning-vs-micro-learning-are-same

Torgerson, C., \& Iannone, S. (2019). Designing microlearning. American Society for Training and Development. Alexandria, VA: ATD Press.

Vaughn, S., Schumm, J. S., \& Sinagub, J. M. (1996). Focus group interviews in education and psychology. Thousand Oaks, CA: Sage Publications. 